\title{
The Hysteric Belongs to Me: Helen Oyeyemi's The Opposite House ${ }^{\mathrm{I}}$
}

\author{
Nó́mi Albert \\ noemi.albert916@gmail.com
}

\begin{abstract}
The term hysteria has undergone several substantial changes throughout its history. A charged concept, deemed for a long time as pejorative and offensive to womanhood, it has lately been re-appropriated for literature under the concept of the "hysterical narrative." This new trend purports to redeem hysteria and, together with it, redeem the feminine and show all its complexity. Helen Oyeyemi's 2007 novel, The Opposite House, conflates the private and the public in two female characters, one human, the other divine. Through this double perspective the work self-reflexively re-evaluates hysteria both in the self and in the community.
\end{abstract}

Keywords: Oyeyemi, hysteria, femininity, humanity, gods.

\section{Introduction}

Helen Oyeyemi's 2007 The Opposite House invites its readers to embrace the hysterical nature of its narrative, and it consciously and purposefully chooses the 'hysterical' adjective as its central characterisation. The novel's main character is Maja, a young British daughter of Cuban immigrants, who, while expecting her first child, strives to come to terms with her identity, with her hybridity. In parallel to her story, interspersing Maja's struggles with highly poetic segments, is the fantastic story of a Yoruba Goddess, Yemaya Saramagua, through whom the novel reworks the transatlantic journey of Nigerian slaves and their faith.

The Opposite House blends Africa and Europe: distant places, differing cultures and various religions. Maja and Yemaya, the two protagonists are different versions of the same persona: they come to represent not just the complexity inherent in identity, but also the difficulties in recognising and embracing a hybrid identity, one that spans continents and cultures. Majas struggles are manifested through an alter ego she calls her personal "hysteric," an entity that takes over control in moments of crisis and actively shapes the fate of the protagonist. And Yemaya with her own parallel fate mirrors this life and further deepens the femininity of the girl.

1 Supported by the ÚNKP-19-3 New National Excellence Program of the Ministry for Innovation and Technology. 
Nowadays, we can talk about the so-called "hysterical narrative," a new trend in literary criticism burgeoning in the 1980s, which, in Elaine Showalter's words, "has developed at the busy crossroad where psychoanalytic theory, narratology, feminist criticism, and the history of medicine intersect" (1993, 24). Showalter presents an acute diagnosis and criticism of this "hysterical narrative" that was born at a time when psychoanalysis and doctors rarely utilise the concept anymore, instead moving into the sphere of literature and media. As she maintains, hysteria enjoys great attention and a new interest as it is "spread by stories circulated through selfhelp books, articles in newspapers and magazines, tv talk shows and series, films, the Internet, and even literary criticism" $(1997,5)$.

Showalter's misgivings lie in the recognition that the "hysterical narrative" has become synonymous with women's writing in general (1993, 24). Hysteria has become the term for all things feminine, for literary texts written by female authors, for fragmentary, complicated narratives, for artistic works problematizing remembrance and time. Indeed, it is a dangerous label, carrying substantial historical weight one cannot bypass. It seems that women writers, critics and thinkers wish to re-appropriate it, to make it their own. This may be the motivation behind a contemporary novel's focus on such a controversial concept, deemed for a long time pejorative and offensive to womanhood. Oyeyemi's text chooses a selfreflexive and ironic take that, nevertheless, is combined with the wish to redefine and redeem hysteria for femininity, for humanity at large.

Hysteria as diagnosis has been around for centuries: as psychoanalyst Anouchka Grose states, the term "hysterikos" was used as early as before the fourth century BC for different "feminine" complaints such as "bad moods, seizures, and morbid thoughts - all of which were believed to be brought about by problems of the womb" (2016, xv). As the name itself means "of the womb," the tight association of the diagnosis with the female sex became inevitable. One of the most emphatic examples is the theory of the wandering womb, originating from ancient Greece. The theory is based on the supposition that the womb moves inside a woman's body, causing her numerous ailments. It was believed that pleasant smells attract it, whereas it flees foul ones, and thus it can be enticed into floating back into its place. Interestingly, although the theory was discredited quite early, the use of smelling salts in the $19^{\text {th }}$ century attests to it still being accepted as an issue (see Gilman et al. 1993, 14-28).

The greatest motivation behind many of these theories lies in attempts at understanding woman, her physical and psychological states, her self. Hysteria as a clinical condition was "invented" (Didi-Huberman 2003, 3) only at the end of the nineteenth century, by Jean-Martin Charcot, who in the 1880s demonstrated symptoms in lectures where he used live subjects (Devereux 2014, 23). Charcot's 
student, Sigmund Freud turned his attention towards hysteria and, together with Joseph Breuer, developed the new science of psychoanalysis (Devereux 2014, 24).

The real change came with Freud, whose theories turned from physicality to the psyche as he started looking for internal scars produced through trauma or repression. Freud furthered his theory by focusing on women and deducing that hysteria is a gendered pathological state, the result of women lacking male genitalia, and hence being scarred from as early as being born. As he writes, "the hysterical neurosis is nothing but an excessive overaccentuation of the typical wave of repression through which the masculine type of sexuality is removed and the woman emerges" $(1962,124)$.

Oyeyemi's novel chooses to take stock of this history of hysteria: it does not shy away from reactions to these earlier theories concerning femininity, such as Maja's stern claim that "[h]ysteria has got nothing to do with an empty womb" $(2007,223)$, reflecting on the wandering womb theory of earlier times. It does not purport to erase the painful, even embarrassing past, but rather intends to face and challenge it in order to reappropriate hysteria.

There is a constant ironic undertone to the quasi-character of the hysteric. To use Mark S. Micale's words, hysteria became a term used "as a dramatic medical metaphor for everything that men found mysterious or unmanageable" in women $(1989,320)$, and indeed Oyeyemi takes advantage of that. The novel embraces its characters' femininity, their complexity, and it constantly moves at the threshold of sanity/insanity. One of hysteria's greatest appeals for the novel can be summed up by Derritt Mason and Ela Przybylo's introduction to ESC: "hysteria is a 'great disorder' because it exceeds definition, escapes conclusive analysis, and persists as a slippery, enigmatic possession of the body; hysteria is a disorder that, in turn, disorders" $(2014,1)$. As I will show, in The Opposite House the hysteric is the embodiment and manifestation of the complexity of feelings and issues the protagonists exhibit and face. It is the very symbol of the ineffable.

The power the hysteric emanates in Oyeyemi's novel makes us recognise that it is actually more than a disorder: it is a statement. As Cecily Devereux formulates it, when hysteria becomes an integral part of feminist theory, it is no longer understood as a medical disorder, but a cultural condition, "an embodied index of forms of oppression" $(2014,20)$ that represents the "feminist reaction and resistance to the patriarchal oppression it indexed" $(2014,21)$. Although numerous feminist critics embrace hysteria and wish to reclaim it, Showalter feels that Freud's work has had such a negative effect on the conflation of womanhood with hysteria that as a result the label "hysterical" denigrates women's writing as art, and "has long been a device of ridicule and trivialization" $(1993,33)$.

Although Showalter's misgivings about this re-appropriation of hysteria by the feminists raise important issues to consider, the focus of this essay is dictated by 
Oyeyemi's novel, one that seems to coincide in its creed with that of the second-wave feminists "to recuperate hysteria and its hysterics from those silences and invisibilities perpetuated by the patriarchal legacy of psychoanalysis," as Mason and Przybylo put it $(2014,7)$. Devereux defines this new approach as a "process and a methodology [...] of destabilizing the system within which the meaning of femininity is fixed, by mobilizing a language that separates words and meanings" $(2014,29)$.

In the next section of the essay, I wish to outline the different manifestations of hysteria in The Opposite House and the multifarious motivations behind them. I propose to show how Oyeyemi chooses to utilise the various conceptions about womanhood and about hysteria, many of them problematic, and makes them the novel's own. Albeit sometimes with irony, the novel consciously appropriates all supposed aspects of the hysteric, by choosing female characters who embrace their personality in its complexity, even showing signs of madness. This novel chooses to guide its readers into the innermost depths of these women, and thus hysteria (and ultimately womanhood itself) is redefined. Placing in the centre of my investigation one of the novel's protagonists, Maja, I examine her femininity and relation to her hysteric (sometimes together with the other female characters of the novel). I start from the greatest manifestation of her hysteric, achieved by her pregnancy and captured through the German concept of Gelassenheit. In this unit the novel's two protagonists (Maja and Yemaya) are presented as having interlinked fates. Yemaya Saramagua, the Yoruba goddess of pregnant women, is proven to possess the pregnant characters of Oyeyemi's novel and to bring out the hysteric in them. The third unit of the essay analyses Maja and her hysteric through a close look at Alfred Hitchcock's Vertigo (1958), a film that shows the complexities of womanhood, most emphatically through the conflation of female autonomy and the male gaze.

The fourth unit investigates woman's relation to food, her problematic link to consumption and the novel's various foci on how woman is defined through these. As women in The Opposite House all exhibit different aspects of this relation, their analysis further broadens the view on the various aspects of womanhood itself. It is telling that in connection to consumption the hysteric appears to take possession of the women of Oyeyemi's novel: aggressive possession that leads to signs of madness on the women's part.

The last section purports to show the process through which Oyeyemi's novel appropriates hysteria, how it turns the hysteric into an inseparable component of woman's identity. The novel seamlessly weaves opposing states, differing spheres together, thus creating free passage between various worlds that come to symbolise the complexity of woman. Dichotomies are annulled, and instead woman is presented as an amalgam of states, of impressions, of selves, even. 
The four distinct units come together to present a detailed view on how Oyeyemi, through her 2007 novel, redeems hysteria for womanhood, takes charge of it, together with its complex, problematic history, and with its help, sheds light on the intricacies, on the beauties, but also on the dangers and hardships of womanhood itself.

\section{2 “The Longing to Let Go"}

In The Opposite House two worlds - the ordinary and the supernatural—seamlessly weave into one another, with the characters becoming doubles or alter egos for each other. The hysteric, Maja's alter ego, both nurturing and destructive, is a force that creates the link between the two worlds, a force that links Maja with Yemaya Saramagua, the Orisha of the Yoruba religion. Majas hysteric creates a deep, instinctual connection that seems to truly unfold in her pregnancy. Pregnancy and motherhood are central aspects of the formation of womanhood in Oyeyemi's novel. Showing women under the influence of their hysterics, the text reaches its apex through the depiction of pregnancy, one that shows the complex, often problematic relationship woman has with her body, and with the foetus growing inside her. This very complexity is captured through the different manifestations of the hysteric, and through the phenomenon of Gelassenheit.

Maja and Yemaya are two facets of the same self, one human, the other supernatural. With names that mirror each other, the women connect again and again, they unite and then split again, and thus show how their fates are inextricably linked. The textual organisation of Oyeyemi's novel reflects this interconnection, with two narratives that are not separated by chapter titles: they alternate in every chapter, often seamlessly weave into each other, almost imperceptibly take over, and shift voice, point of view, time and place. ${ }^{2}$

Maja's first-person narrative, the personal, intimate story of a black Cuban girl living in London is extended and opened into the exotic and intricate world of Yoruba mythology, one that creates the link between Lagos and London (literally

\footnotetext{
In the novel we can notice a heightened attention on the intermingling between prose and poetry, which creates the textual fluidity of Oyeyemi's prose, and seems to be the manifestation of femininity itself. Furthermore, it also seems to function as a reflection on the state of the hysteric, as a manifestation of woman's inner and outer conflicts, the symptom of a deep-seated anxiety. Emily Dickinson's poetry suffuses the stories: creating an amalgam of different realities, with the help of the fluid style of the poetic segments, Dickinson's poetry heightens the eerie atmosphere of the novel. Oyeyemi borrows most of her chapter titles from her, with "tell it slant" becoming the motto of a writing that is both prose and poetry: it is elusive, defying all expectations, with no linearity, with no logicality.
} 
through the two doors found in the basement of Yemaya's somewherehouse), or rather Lagos-Habana-London, three places that together comprise a difficult hybridity. Part of this hybridity manifests itself through Santería, which is "a complex of religious cults in the Afro-Cuban population, combining Yoruba African and Spanish Catholic traditions, especially concerning the saints (santos) who are identified with the spirits (orisha) of the Yoruba pantheon" (Bowker 1997, 856). It became the symbol of resistance and perseverance, the migrant's only tie to their lost home. Santería is defined by this visible duality of worlds, identities and religions. Slaves brought it to Cuba, where it was further developed in the late eighteenth and early nineteenth centuries. The narrator of The Opposite House, however, tells a slightly different story. The Orisha become more than symbols or detached deities, they suffer together with the humans:

The Yoruba gods discovered their Cuba in the dark, hidden in bigger emergencies and cries of warning as patrol ships tried to intercept the cargo. The gods were hidden in the fear of being drowned. They were hidden in the unseen smack, smack, smack of the next man's head on the ship's boards as he tried to damage his brain and decrease his market value. The gods were not afraid, but they wept. (Oyeyemi 2007, 23-24)

These images make the journey, the fates of the gods and of people more present than ever, wounds and pains are palpable in this poetic language. The journey of the Orisha reframes the hardships suffered by the slaves, and it reflects on the fate of black people in Cuba as they embraced this mixed religion: "On arrival, Orishas became beloved in secret. Slaves had to be Catholic and obedient or they'd be killed, or worse" $(2007,24)$. Chabella, Maja's mother touches upon the religion's great significance when she states: "I suppose El Jefe was right to be nervous that something was going on with Santería. Something is going on. Those West Africans brought another country in with them, a whole other country in their heads" $(2007,107)$. This shows that even though physically Afro-Cubans were robbed of their home, their memories and beliefs could not be taken away from them.

Yemaya Saramagua, an Orisha, or goddess of Santería, is a highly elusive character in the world of The Opposite House, a spirit that is worshipped by the followers of the religion, but also a person who suffers together with them, who shares their fate, their hardships. She becomes the symbol of the migrant, the symbol of hybridity, and thus she provides a rich projection of Maja, the novel's human protagonist, and her struggle to find herself. The poetic, elusive narration recounting Yemaya's life in the somewherehouse is both a counterpart to Maja's more prosaic, more ordinary life and a key to understanding the complexity of feelings identified in Maja and her peers. As Kamila Shamsie remarks, the two women "reflect a condition of being adrift" (2007). 
Yemaya, who is the patron of pregnant women, is the one whom Maja needs as she is expecting her first child. "I have strangeness in my family" (Oyeyemi 2007, 120) resonates with a shared history (or "hystory," to use Showalter's term, 1997) of possession, of women identifying with the Yoruba goddess. As the goddess protecting pregnant women, Yemaya visits Chabella, too, during her pregnancy with Tomás, Maja’s younger brother.

Witnessing her possessed mother becomes a defining memory for Maja. One day her Mami descends the stairs "wrapped in nothing but a cloth of preternatural white, with strands of her hair swimming around her face, strands of her hair tied with little flags of white cloth" $(2007,107)$. Her entire body becomes a canvas for an overflow of feelings, and for the life slowly developing inside it: "Tomás became part of the outfit too: [...] it was he that made the white flow" (2007, 107). Chabella is in a trance, looking "wild, wilder than animals," a trait pregnant women seem to share in the world of The Opposite House. As she dances, Chabella becomes "Yemaya Saramagua, a sure, slow swell in her arms and her hips like water after a long thirst, her arms calling down rain, her hands making secret signs, snatching hearts" $(2007,108)$.

Similarly, Majas entire body gets under the influence of her hysteric, which is re-enforced by her son growing inside her. She senses that "something is happening here, something that doesn't fall into good, OK, or bad" (2007, 120). Maja is not alone in this disturbing state; she acknowledges herself as a member of a long line of women who might have gone through similar experiences ("I have strangeness in my family, a woman who was a priest when she wasn't supposed to be," [2007, 120]), struggling to affirm themselves, to find their true selves.

Mother teaches daughter about Gelassenheit: "the longing to let go and collapse under holy madness" (Oyeyemi 2007, 10). This Gelassenheit, according to Anita Harris Satkunananthan, is the result of these women's state of being between realities, with a hybrid voice, which results in an elision between cultures (2011, 57). The German concept's accentuated position further complicates the texture of the novel, since it activates a Western philosophical idea that interweaves with the Yoruba mythology. The Gelassenheit Maja inherits from her foremothers seems to coincide with Heidegger's concept, explained by Nathan A. Scott as "the spirit of disponibilité before What-Is which permits us simply to let things be in whatever may be their uncertainty and their mystery" (1969, xiii). Gelassenheit overpowers Maja in moments of crisis. The word resonates in her ears, and its power takes charge:

I lift my head from his shoulder and touch my lips to the skin that crinkles over his Adam's apple. My teeth latch onto him and I clamp down hard, so hard that my teeth find each other again through his skin

(he shouts) 
and I am not thinking anything in particular, just that I have to hurt him. $(2007,181$, emphasis in original)

We see a woman who has lost control, has become a monster, driven by a hunger for pain. She is reminiscent of the Western image of the vampire, or the embodiment of the soucouyant, the Caribbean soul-eating entity (Satkunananthan 2011, 44). Alison Rudd rightly points out the composite nature of the soucouyant, a phenomenon that comes to represent the mixture of cultural influences the women of The Opposite House internalise: in Rudd's words, it is a "hybrid of vampire, ghost and zombie" $(2010,51)$. The phenomenon captures Majas liminal state and her resulting obscurity, her desperate search for some cultural certainty.

Besides this aspect, however, one cannot ignore the sexual charge of this manifestation. Bloodsucking itself is sexual "with its penetration of a supine body and exchange of bodily fluids," and hence the soucouyant embodies female sexual voracity (Anatol 2015, 65). Majas outburst becomes part of her being under the influence of her hysteric, her alter ego that reinforces her female identity. Her sexual body becomes the centre of all experiences, the outlet through which she expresses herself. That is how her previously cited instance of Gelassenheit, her surrender to madness, condenses the complex nature of her mental and physical state in pregnancy.

Majas body, tightly linked to the new life gradually forming inside it, takes over language, becoming the most accurate communicator of her intricate state. It projects her mental state, it reflects all her struggles and conflicts. Although she has been waiting for her son since she was a young child, Maja's relationship to her unborn son is complicated, often inimical. Just as with Chabella expecting Tomás, the foetus is at once part of the mother's body, but is also given autonomy and power. Maja dreads her son's approach, and as a result her own body becomes dangerous and even alien: "I am scared to touch my stomach, not because it is tender, but because it has begun to swell beyond the point where it can be comfortably rubbed with one hand. If I cup it with both hands the bump might rise to the space I allow it" $(2007,98)$. The gothic traits of this relationship are evident (see Buckley 2017, 41).

Pregnancy is thus presented as a highly problematic issue, raising great insecurities, even conflicts inside a woman. There is an inherent resistance which shows that motherhood is problematic. In Helen Cousins's words, "[f]or Maja, who has always expected to have children [...] pregnancy is experienced as an almost malign seizure of her body" $(2012,14)$. She resists her son by "eating crap," but later gives in to his demands: "the boy needs seeds and fresh fruit and oily fish and folic acid and carefulness and stuff" $(2007,8)$. This portrayal of motherhood is another instance of the novel going against traditional representations of womanhood/motherhood: it refuses to present pregnancy as a perfect, blissful 
state in which the woman radiates happiness, and instead chooses to exhibit the darker aspects of this state through the various connotations of the hysteric.

\section{3 "A Vast Wound"}

Maja and her childhood friend, Amy Eleni are deeply preoccupied by the phenomenon of doubling, of having an alter ego, which in their case manifests itself as their personal hysteric. It is no wonder, then, that Alfred Hitchcock's 1958 Vertigo, a film that builds heavily on doubles, on doppelgängers, catches the attention of the girls. As critic Peter Matthews notes, at the core of Vertigo there is a "delirious excess that paradoxically borders on abstraction and renders the film a true nonpareil in Hitchcock's career" $(2018,55)$. Maja and Amy Eleni are so infatuated with Hitchcock's film that its viewing becomes a regularly enacted ritual. Seemingly each viewing enriches the array of interpretations and, alongside them, the two girls' relation to the film and to themselves. I interpret the film to function in the fictional world of Oyeyemi's novel as a further deepening of the main focus: of the focus on the intricacies of womanhood, on the array of personalities housed in woman, but also of a focus on madness.

The two girls' infatuation with Vertigo in Oyeyemi's novel seems odd at first. The first half of the film is pronouncedly governed by the perspective of its male protagonist, Scottie Ferguson, as it is his gaze through which one views Madeleine. Maja and Amy Eleni's interest in Vertigo is even more accentuated because of Scottie's overbearing transformation of Judy Barton into Madeleine Elster, coupled with her obvious reluctance and unease. But this film represents many experiences for the fictional characters of Oyeyemi's novel. Madeleine becomes a symbol that stands for womanhood on the one hand, and trauma on the other. Maja interprets her in the following way:

You know that Madeleine is in big trouble because she's a vast wound in a landscape where wounds aren't allowed to stay open-people have to shut up and heal up. She's in trouble because the film works to a plan that makes trauma speak itself out, speak itself to excess until it dies; this film at the peak of its slyness, when people sweat and lick their lips excessively and pound their chests and grab their hair and twist their heads from side to side, performing this unspeakable torment. (Oyeyemi 2007, 34)

Madeleine is the embodiment of painful memory, of the past intruding into the present and robbing the character of her present. Maja, in her sensibility, recognises this and identifies a similar experience in herself being separated from her past life but still under its influence. In the movie Scottie believes that Madeleine is haunted (which seems like a common motif the film shares with Oyeyemi's novel), even 
possessed by the spirit of a woman who had been taken advantage of, robbed of her own child and cast aside. Carlotta Valdes, this spirit from the past enters the present through her doppelgänger, Madeleine Elster, who wants to commit suicide similarly to her ancestor. Through Carlotta the film turns into a "meditation on time and its illusory conquest," to use Richard Allen's words $(2011,578)$. Madeleine becomes the embodiment of both Carlotta and Judy; the three fates are interlinked, and they all are "objects of love reincarnated, remade, over and over" (Duncan 2004, 132).

Madeleine is doubly abstracted and manufactured: first by Judy and Gavin Elster, who together create the image of a disturbed woman whose fate is doomed; secondly, Judy is again transformed, this time by Scottie, into the Madeleine he believes he knows. And this woman is never real; not only because she is created, but because she exists through Scottie, through his gaze. He never sees the flesh-and-blood human being: he falls in love with a romantic mirage. Madeleine herself is never present, instead she is an unattainable, lost past: her entire persona, her mostly wordless, expressionless detachment gives her an eerie quality. For instance, as Susan White remarks, her trancelike state among the sequoias "speaks of the invasion of the present by the past, of Madeleine as an immutable object of desire" $(2011,189)$.

After Madeleine's (both real and symbolic) death, Judy could gain existence as herself, but Scottie's supposed memory of his lost love forbids the present from manifesting itself, and thus Judy from existing. Nevertheless, although the male perspective seems to rule the film, and to rule the women, the issue is more complex. When Judy appears, the viewers encounter a woman who has recovered her reality and abandoned her abstract nature. Through this shift in portrayal and approach, I believe, together with Nicholas Haeffner, that Hitchcock's film reveals "an oscillation between identification with and objectification of women" $(2005,80)$. The numerous doubles and dichotomies the film operates with are appealing to the two girls of Oyeyemi's novel, who being young and on the brink of womanhood, find themselves between the male gaze and their own autonomy.

Maja and Amy Eleni can identify with the two states symbolised by Madeleine and Judy, played by the same actress. The great difference in sameness, in one person is what the protagonist of The Opposite House and her best friend defiantly embrace. This is what they call their "personal hysteric" $(29,31,223)$ : a denomination that in itself signifies the duality of man and woman, object and subject. Oyeyemi's characters take charge of the concept of the hysteric, and redefine it, turning it into a symbolic gesture of women reclaiming their selves and the gazes projected at them. Although it seems that Scottie dominates Madeleine/Judy, the film gradually reveals woman as an autonomous entity that chooses to play the roles ascribed to her.

Vertigo is the symbol of Majas own complex, compound subjectivity, with the woman both as herself and as seen by the male gaze. She is accompanied by her 
personal hysteric, and haunted by a memory, by a country that may prove to be an illusion. Her experience and her persona in The Opposite House are mirrored by the spiral of vertigo, which "suggests the impossibility of attaining a final truth about woman - and hence about man" (Modleski 2011, 180). The particular feeling of unsettledness, or a specific unease is what pervades Maja's world in Oyeyemi's Opposite House, and this is the state that draws her to Hitchcock's movie.

\section{4 "Stapled [...] stomachs"}

Womanhood and its complex nature reach another manifestation in the novel through the issue of consumption. Food and eating have been recognised as a constant issue for women, and this relationship shows different aspects for different races and cultures. Oyeyemi's novel presents women coming from different backgrounds, who all exhibit signs of a very distinct relation to consumption. As I intend to prove in the following, these signs ultimately connect consumption with hysteria, where eating or, more often, the refusal to eat is the hysteric's statement of resistance.

The complicated relationship between mother and son is presented through consumption: "Food: everything I eat, my mouth lets it go, my stomach heaves painful, sour streams," notices the pregnant woman, drawing attention to pains, or even to possible resistance against the foetus $(2007,16)$. Food and eating become the exteriorisation of Maja's psychological states. Her entire body seems to decay: "My breasts are rotten lumps hooked into my ribcage, and I can't touch my body at all, I can't" $(2007,16)$. Maja is distanced from her own body and from her sanity. This body, taken over by the baby, feels alien and distant, forced into eating. When Aaron, Maja's boyfriend rather forcefully feeds her, she becomes objectified into a body that needs to pass food to the foetus inside: "In his eyes I am a throat working down red juice, I am a shaking hand and a spoon and beyond that his baby" $(2007,231)$. Buckley recognises that "[i]n this novel, both children and mothers regurgitate food, expressing a double abjection that suggests this pouring of desire into the child is insupportable on either side" $(2017,54)$.

Besides her pregnancy, Maja’s life story shows other instances when her relation to food symbolises her hardships. The girl is caught between two worlds, and she struggles to conform to one or the other when, for instance, in her adolescence, she decides to lose weight and starts living on the smells of things. "When Chabella showed me recent pictures of my dimpled, glossy-haired cousins in Habana Vieja," says Maja, she is happy, because-despite all their obvious advantages—she still considers herself more beautiful, simply because she is thinner than them $(2007,51)$. Eating and other bodily functions connected to it are complicated by the historical 
and cultural backgrounds of the characters, which seep through the dinner table. Sarah Ilott recognises the special importance given to food in the novel, noting its role as a link to the past, with the mouth becoming "a site of historical memory" $(2017,147)$. She calls the mouth an "open wound" that signals the difficulties of the migrant state, the incompleteness of identity formation $(2017,148)$.

Another instance of eating and its entailments sheds light on the connections between consumption and womanhood, showing how the former can become an expression of the latter, and ultimately of the resistance of the hysteric. Amy Eleni's mother Despina refuses to eat and even though, according to her daughter, she is not anorexic and "doesn't give a shit about her weight" (2007, 141), her looks are unnatural, possibly even approaching the monstrous: "Despina is thin like being naked in public_-you can see the beginnings of her teeth stamped in her face; you can see them through her skin when her mouth is closed" $(2007,115)$. Her effect on the girls is akin to that of the formerly mentioned soucouyant, who sucks the life out of all the girls around her. Only the father can eat freely, but "Despina stapled our stomachs with a tranquil gaze," remarks Maja $(2007,116)$. The girl parallels Despina with mothers from Chabella's apataki, creatures of mythology who are feared to eat their children's spirit $(2007,116)$.

And indeed, mothers in the world of The Opposite House are fearsome, and now and again they attack their own children. Despina, with her piercing gaze, forbids her daughter from eating, and hence strips her of power, of autonomy. Between Chabella and her daughter there is also a constant friction sensible through Maja's narrative. The mothers in this novel present the often inimical relationship between mother and child, the imperfections in its dynamics. They all show signs of hysteria, which becomes the manifestation of all their tensions. In psychoanalyst Bracha Ettinger's words, hysteria "is a mode of subversion and resistance" $(2005,135)$. It seems that in Oyeyemi's novel hysteria becomes, above all else, a mode of resistance: resistance against patriarchy, against social conventions, against assimilation.

The volatility between Chabella and Maja reaches its apex when the mother tries to strangle her own daughter. Chabella attacks her daughter in a complex scene in which Maja and her mother witness a woman being raped on the street below their home. When Maja starts dialling the police, it seems that Chabella is overtaken by her hysteric: "Mami kissed my forehead, her arms dropped down around me; I stiffened because she was laughing and crying at once and I didn't know what it meant. Her hands clasped around my throat, and when I looked into her eyes I couldn't find her. Instead I saw something inky and strange rising" $(2007,149)$. Chabella loses control and, overwhelmed by her hysteric, tries to rob her daughter of her voice, because she herself does not have one: Chabella does not speak English, she cannot communicate with the police, and thus she feels threatened. 
This becomes a paradigmatic moment in Maja's life, one through which she learns that she needs to protect her throat, her voice $(2007,149)$. Her throat becomes her most feared treasure, one that she always shields with all her power. Knowing this, the instance of Aaron force-feeding her gains further weight, as her most cherished member is under attack. Her throat, her voice thus becomes a central motif for Majas "struggle for articulation and expression" in The Opposite House (Satkunananthan 2011, 41). The digestive system and the vocal chords are closely tied to express the protagonist's identity crisis, who is caught between two worlds, between two selves. What her throat, her vocal chords represent to Maja is a "struggle for agency" (Satkunananthan 2011, 42) that is extended to become the central focus of Oyeyemi's novel.

\section{5 "Like Every Girl"}

Maja's alter ego, her personal hysteric seems to be an integral part of her psyche, an entity that accompanies her everywhere: "she is blank, electricity dancing around a filament, singing to kill" (2007, 29). It is elusive and dangerous, both appealing and repulsive: "designer made [...], flattering and comfortable," it is always lurking, waiting to take over $(2007,29)$. The hysteric as a distinct aspect of Maja's subjectivity is a defining element of her life, and it gets special attention in her narrative. The emphasis is peculiar, since it invokes more than one issue in connection with hysteria, femininity and trauma, through which, on the one hand, the novel destabilises the boundary between sanity and insanity, and on the other, it presents hysteria as an integral part of womanhood.

In an interview given to Michel Martin, Oyeyemi seems to imply that Majas hysteric reflects on the hardships of being a young woman, of getting by in general. ${ }^{3}$ And indeed, the first presentation of the hysteric does facilitate a reading of communal sentiments ("Like every girl," Oyeyemi 2007, 29) standing behind

"MARTIN: I don't know why I love this so much, but I think-well I guess I wanted to ask you: Why does Maja have a hysteric? Does she have a hysteric because she's so out of place in the world? Does she have a hysteric because she's a young woman and it's just not that easy being a young woman in the world these days?

Ms. OYEYEMI: Yeah. I think it's the young woman thing very much. I feel that very much as well. And it's just this whole kind of almost a pressure to appear and not to be, as if there are parts of yourself that you need to tuck away. And, I mean, this is the whole expression of anger, for example, and like raising your voice and stuff. That's actually quite an interest thing that my sister and I were recently talking on, and we realized that we both talk quite quietly. People are always asking us to speak up and stuff. And we realized it's because, when we were younger, our dad used to say stop shouting when we were just talking at normal pitch of voice. And we were like, we're not even shouting." (Martin 2007) 
the conception of the hysteric, presenting it as something ordinary and normal. Through the generalisation that claims that every girl has her own hysteric, through the casual relation to instances of self-abuse and suicide attempts, the hysteric becomes a vehicle through which mental instability is approached by the novel. In some instances, the manifestation of the hysteric is presented as something "normal," and sometimes it is enveloped in such a heightened lyricism that it makes even self-mutilation beautiful:

One night, drunk, drunk, drunk, I dropped my empty shot glass and a full for Luke, sat down beside the pieces and arranged them in my skin, twisting clear flowers planted to grow from my soles, my arms. It hurt. But wearing my hysteric, it became a matter of art and pain and so on. It was extreme, it was because of tension. $(2007,29)$

As reviewer Olutola Ositelu remarks, by "presenting it in an everyday-almost mundane"-manner, Oyeyemi "makes the reader aware of how easy it could be to cross the sanity line, how things that should raise alarm can become quite routine and ordinary to the sufferer" (2007). There is an effortlessness to the hysteric as it takes over, as Maja gives in to it.

Oyeyemi's The Opposite House filters the traumatic experience and the crisis of the self through the phenomenon of hysteria. Great emphasis is placed on the relationship between hysteria and time, the subject's connection to their past in particular. As Mason and Przybylo maintain, "hysteria dwells in a kind of forgotten time or timelessness", it always has a problematic relationship to time: "hysteria seems to collapse, stretch, and distort time, resisting linear temporality" (2014, 14). It is Freud who first formulates the hysteric's peculiar relation to time. In one of his lectures entitled "On the Psychical Mechanism of Hysterical Phenomena," he writes that in hysterical patients there are only impressions that they cannot evade $(1962,37)$, which means that reality and imagination (or impressions) are interchangeable, and an impression can become more real than the real. The hysteric's relation to time is paradoxical: the hysteric is "before and elsewhere" (Kristeva 2010, 132, emphasis in original), inhabiting a sort of "dead time" $(2010,132)$.

The protagonist of Oyeyemi's novel is stuck between past and present, between Cuba and London. Her relation to time, to her life is contradictory: sometimes she wants to get rid of her past life, forget all about it, other times she believes her entire identity depends on her Cuba memory, shards of memory leading her back to a time when she was very young, still living in Habana. She both wishes to discard this past self and clings to it madly. The reader finds her in this conflict, which is polarised by her pregnancy. Bringing a new life into the world prompts a crisis of meaning in the protagonist, who starts to desperately pursue her own self and meaning. 
Maja's hysteric manifests itself in peculiar ways, and it is symbolised by her different body parts, such as her hair. Hair is a complex motif in The Opposite House, one that represents the greatest intimacy, closeness, expressed through corporeal connection. It "is at the cutting edge between the material and the figurative" (Cooper 2008, 53). Showalter's redefinition of hysteria as "a universal human response to emotional conflict" $(1997,7)$ reveals it to be a visceral experience of crisis, caused by a past trauma that the subject is incapable of processing. Maja's hair is gradually revealed to be the representation of her femininity, of her identity, and it also comes to represent the traumatic experiences the girl goes through. When a boyfriend makes her cut her hair, she exhibits signs of disturbance, which the boy registers: "he said he was unhappy that I didn't seem to love my hair in its natural state" $(2007,30)$. This instance shows a poisoned individual who is coerced into surrendering herself. The result is visceral: "I ran a bath; the hysteric came and I was persuaded to try and drown myself" (2007, 30). Maja and her reaction show how her body becomes the communicator of her inner struggles. As psychologist Richard A. Chefetz states, "hysteria is not always describable via language because traumatic emotional experience is partly embodied" (2017, 83).

Maja's hair and hysteric belong together, and they are there to forbid Maja from surrendering her power, her identity. It is not surprising then that her hair is difficult to manage, and it is Amy Eleni (who also has a very distinct idea about her own hysteric) who can handle it. Amy Eleni knows Maja, knows her hair, and thus she brings out a new "personality" from them: "really my hair is simple-once it is washed and fed with coconut oil, it sighs and falls asleep" (2007, 67). Maja's hair emphasises her femininity, separates her from men, but it also highlights her African origins. In Brenda Cooper's words, " $t \mathrm{t}]$ he visceral texture of African hair stands for the racism that unites black people's experience outside of Africa" (2008, 53). This realisation brings the hair closer to Maja's hysteric, since both manifestations prove to have dual roles for her. They anchor her to her past, to her origins, and thus they are meant to help her maintain her identity; but this anchoring, since it happens in the Western world, always singles her out, never allows her to truly belong. It ultimately leads to a sense of liminal existence, Maja finding herself between two cultures, belonging to neither of them.

Cousins discusses the alien aspect of this experience, too, when she focuses on the subject's positioning between two cultures. As she states, women are "expected to retain aspects of the 'traditional' through multiculturalism's insistence on diversity (often reinforced by their own patriarchal cultures), they are also required by multiculturalism to conform to the host culture by dispensing with aspects of 
traditions which discomfort the host" $(2012,13)$. In Maja's case hair is a visible link connecting her to her African identity, and she notices how African mothers ban their daughters "from straightening [their hair] and [instead help them] comb [it] out into a fan" (Oyeyemi 2007, 93). But this, and its manifestation as her hysteric, is exactly the force that prevents Maja from conforming to the Western world, and thus finding a new home there.

The destructive nature of the hysteric is revealed most expressively through instances when it urges Maja to take her life, such as her realisation that "[ $t]$ here's someone inside of me, and she says I must die" (2007, 35). Although sometimes liberating, the hysteric is rather possessive, keeping Maja under her influence. It takes over her body, just like Amy Eleni's hysteric does with hers: it "walks three paces behind me at all times, and when it's all a bit much, I kind of hang back and she kind of hurries forward, and she jumps on my back and takes me down. Then she stands up in my place" $(2007,31)$.

Oyeyemi's novel shows hysteria in all its complexity: how it is an integral part of being a woman, at once protective and destructive. The Opposite House sheds light on the quasi-paradoxical nature of the hysteric, of its characters' alter egos, through building heavily on a system of dualities (sanity/insanity, nurture/inhibit, ordinary/supernatural, physical/metaphysical, etc.). The threshold between the opposites is constantly surpassed, and woman in the novel easily navigates between the two states. Through this presentation of the hysteric as natural, as visceral, womanhood itself is redefined and hysteria is reappropriated.

\section{Conclusion}

Maja's life, her ego and alter ego (a.k.a. her hysteric) is sometimes mirrored, other times overtaken by one of the Goddesses of Santería: Yemaya Saramagua. The girl finds herself between two worlds, between her past self and present life, and the novel presents her struggles to find herself, to anchor her existence somewhere in this in-betweenness. The hysteric, which is sometimes malevolent, other times benevolent, expresses the protagonist's identity crisis in the novel. However, the acceptance of this complexity, of the character's psyche is what ultimately gives her solace.

The women of The Opposite House move freely through the spheres of the physical and metaphysical, achieving this freedom through their hysterics. They give in to the practice of Gelassenheit, slowly descending into holy madness, at the limit of voice and silence. Despite all her struggles to voice herself and thus understand her identity, Maja needs to realise that there are things that will never be uttered. 
It is the hysteric through which the characters in The Opposite House reach utter dislocation: they relinquish their body and become passive witnesses to the actions their alter ego-the hysteric - performs. This state plunges the psyche into an abyss, dislocating it from its body, from its surroundings. This holy madness is a powerful trance-like state, connecting the physical world to the otherworldly dimension inhabited by the Yoruba gods.

Maja's willingness to give in to her hysteric is ultimately the sign of her autonomy over her own body, over her fate. The entire novel is angled towards the redefinition of hysteria with the purpose of redeeming it for womanhood. Making use of the rich history of the term, of the psychological state commonly associated with womanhood, meant to denigrate it, Oyeyemi's novel appropriates all these traits and by showing us the intimacy, the ordinary and extraordinary nature of this feminine existence, it redefines hysteria. Maja, as a twenty-first-century woman defined by her past and present, by her personal history and the history of her people, by the advent of her son and the future it brings into motion, retains her essence, her true self through her hysteric. This alter ego is there as a reminder of herself, as a resistance in an oppressive society.

\section{Works Cited}

Allen, Richard. 2011. "Hitchcock's Legacy." In Leitch and Poague, 572-91. https://doi.org/10.1002/9781444397321.ch30

Anatol, Giselle Liza. 2015. The Things That Fly in the Night: Female Vampires in Literature of the Circum-Caribbean and African Diaspora. New Brunswick: Rutgers University Press.

Bowker, John, ed. 1997. The Oxford Dictionary of World Religions. Oxford: Oxford University Press.

Buckley, Chloe, and Sarah Ilott, eds. 2017. Telling It Slant. Critical Approaches to Helen Oyeyemi. Eastbourne: Sussex Academic Press.

Buckley, Chloe. 2017. "Gothic Children in Boy, Snow, Bird, The Opposite House, and The Icarus Girl." In Buckley and Ilott, 38-58.

Chefetz, Richard A. 2017. "Hysteria and Dissociative Processes: A Latent Multiple Self-State Model of Mind in Self Psychology." Psychoanalytic Inquiry 37 (2): 82-94. Taylor and Francis Online.

https://doi.org/10.1080/07351690.2017.1281033

Cooper, Brenda. 2008. "Diaspora, Gender and Identity: Twinning in Three Diasporic Novels." English Academy Review 25 (1): 51-65. Taylor and Francis Online. https://doi.org/10.1080/10131750802099482 
Cousins, Helen. 2012. "Unplaced/Invaded: Multiculturalism in Helen Oyeyemi's The Opposite House." Postcolonial Text 7 (3): 1-16. Postcolonial Text.

Devereux, Cecily. 2014. "Hysteria, Feminism, and Gender Revisited: The Case of the Second Wave." ESC 40 (1): 19-45. ProjectMUSE.

https://doi.org/10.1353/esc.2014.0004

Didi-Huberman, Georges. 2003. Invention of Hysteria, translated by Alisa Hartz. Cambridge: MIT Press.

Duncan, Paul. 2004. Alfred Hitchcock. Harpenden: Pocket Essentials.

Ettinger, Bracha. 2005. The Matrixial Borderspace. Minneapolis: University of Minnesota Press.

Freud, Sigmund. 1962. "On the Psychical Mechanism of Hysterical Phenomena." In The Standard Edition of the Complete Psychological Works of Sigmund Freud, vol. 3: Early Psycho-Analytic Publications, translated by James Strachey, 1-26. London: Hogarth.

Gilman, Sander L., et al. 1993. Hysteria Beyond Freud. Los Angeles: University of California Press.

Grose, Anouchka. 2016. "Reclaiming Hysteria." In Hysteria Today, edited by Anouchka Grose, xv-xxxi. London: Karnac Books.

Haeffner, Nicholas. 2005. Alfred Hitchcock. Harlow: Person Education Ltd.

Ilott, Sarah. 2017. "The genesis of woman goes through the mouth': Consumption, Oral Pleasure, and Voice in The Opposite House and White Is for Witching." In Buckley and Ilott, 132-151.

Kristeva, Julia. 2010. "The Sobbing Girl; or, On Hysterical Time." In Hatred and Forgiveness, translated by Jeanine Herman 129-52. New York: Columbia University Press.

Leitch, Thomas, and Leland Poague, eds. 2011. A Companion to Alfred Hitchcock. Malden: Blackwell. https://doi.org/10.1002/9781444397321

Martin, Michel. 2007. “Oyeyemi's 'Opposite House.” NPR. https://www.npr.org/ templates/story/story.php?storyId $=11384738 \& \mathrm{t}=1615709424329$. Accessed 25 Nov. 2020.

Mason, Derritt, and Ela Przybylo. 2014. "Hysteria Manifest: Cultural Lives of a Great Disorder.” English Studies in Canada 40 (1): 1-18. ResearchGate. https://doi.org/10.1353/esc.2014.0003

Matthews, Peter. 2018. "Vertigo Rises: The Greatest Film of All Time?” Sight and Sound. https://www.bfi.org.uk/news-opinion/sight-sound-magazine/pollssurveys/greatest-films-all-time/vertigo-hitchcock-new-number-one. Accessed 28 Nov. 2020. 
Micale, Mark. S. 1989. "Hysteria and its Historiography: A Review of Past and Present Writings (ii).” History of Science 27 (4): 319-51. SAGE journals https:// doi.org/10.1177/007327538902700401

Modleski, Tania. 2011. "Suspicion: Collusion and Resistance in the Work of Hitchcock's Female Collaborators." In Leitch and Poague, 162-180. https://doi.org/10.1002/9781444397321.ch9

Ositelu, Olutola. 2007. "The Opposite House." African Writing Online. https:// www.african-writing.com/ositelu.htm. Accessed 28 Nov. 2020.

Oyeyemi, Helen. "Helen Oyeyemi Chit Chats about Ali Smith." http://readers. penguin.co.uk/nf/shared/WebDisplay/0,,215063_11_1,00.html. Accessed 8 Dec. 2019. 2007. The Opposite House. London: Bloomsbury.

Rudd, Alison. 2010. Postcolonial Gothic Fictions from the Caribbean, Canada, Australia and New Zealand. Cardiff: University of Wales Press.

Satkunananthan, Anita Harris. 2011. "Textual Transgressions and Consuming the Self in the Fiction of Helen Oyeyemi and Chimamanda Ngozi Adichie." Hecate 37 (2): 41-69. Informit. https://doi.org/10.1093/acref/9780195301731.013.48150

Scott, Nathan A. 1969. Negative Capability. Studies in the New Literature and the Religious Situation. New Haven, Connecticut: Yale University Press.

Shamsie, Kamila. 2007. "The Gods Go Abroad." The Guardian. https://www. theguardian.com/books/2007/may/12/featuresreviews.guardianreview 19. Accessed 28 Nov. 2020.

Showalter, Elaine. 1997. Hystories: Hysterical Epidemics and Modern Culture. New York: Columbia University Press.

—. 1993. "On Hysterical Narrative." Narrative 1 (1): 24-35. JSTOR.

White, Susan. 2011. "A Surface Collaboration: Hitchcock and Performance." In Leitch and Poague, 181-98. https://doi.org/10.1002/9781444397321.ch10 